\title{
Construção identitária da professora de Educação Física em uma instituição de educação infantil
}

\author{
Renata Marques Rodrigues* \\ Zenólia Campos Figueiredo ${ }^{* *}$
}

\begin{abstract}
Resumo: Trata de um artigo que busca compreender como a professora de Educação Física constrói suas identidades, considerando as experiências relacionais vivenciadas por ela com a organização da instituição em que trabalha, com os sujeitos adultos e com as crianças, no contexto da educação infantil. Construímos uma análise da narrativa de uma professora de educação física atuante na educação infantil, buscando trabalhar com alguns conceitos do campo da socialização profissional. Discutimos as identidades docentes como uma das identidades possíveis constitutivas do sujeito no campo profissional, o que evidencia as múltiplas pertenças desse sujeito a campos familiares, políticos, sociais, profissionais.
\end{abstract}

Palavras-chave: Identidade Docente. Educação Física. Educação Infantil

\section{INTRODUÇÃo}

Trata-se de um artigo que representa uma experiência ${ }^{1}$ de análise, anteriormente ao trabalho efetivo de uma dissertação de mestrado, que busca compreender como a professora de Educação Física constrói sua identidade docente, considerando as experiências relacionais vivenciadas por ela com a organização da instituição em que trabalha, com os sujeitos adultos e, principalmente, com os sujeitos criança no contexto da educação infantil.

\footnotetext{
‘Professora de Educação Física. E-mail: renata.m.rodrigues@hotmail.com

"Professora Adjunta do CEFD/UFES. Coordenadora do Práxis - Centro de Pesquisa de Formação Inicial e Continuada em Educação Física. E-mail: zenolia@npd.ufes.br

${ }^{1}$ Essa experiência serviu também como uma estratégia para melhor compreensão do objeto de estudo e para a aproximação com os referenciais teóricos mobilizados.
} 
A noção de identidade adotada por nós envolve as diversas experiências de socialização vivenciadas pela professora, como as pré-profissionais, as profissionais e a experiência adquirida pela prática profissional em um contexto educativo, pois a identidade não é algo estanque e imutável, mas sim um processo contínuo influenciado pelas vivências de cada sujeito. Não desconsideramos esta complexidade na construção identitária ${ }^{2}$, mas propomos discutir aqui, especificamente, a construção da identidade docente a partir da socialização profissional vivenciada no contexto profissional da professora.

A relação entre essas experiências profissionais e o processo identitário evidencia a presença de singularidades na construção da identidade profissional da professora colaboradora. Enfatizamos a centralidade da figura da professora como sujeito da sua própria estória, entendendo que esta singularidade não se refere a uma individualidade na construção da identidade docente, pois a docência remete a um grupo profissional, que também é coletivo.

A professora, como sujeito, não está desligada do grupo dos profissionais da área da Educação Física, que é uma profissão construída historicamente e marcada por discursos de legitimação que permeiam os espaços de formação destes profissionais e, também, faz parte de um grupo de professores que atua especificamente no contexto educativo da educação infantil de um município determinado, o que evidencia a importância e a necessidade de compreender a construção da identidade docente de forma contextualizada. É uma construção ao mesmo tempo individual, pois faz parte da trajetória de vida da professora, constituindo-se como uma construção pessoal que permite ao sujeito fazer escolhas diante do universo múltiplo e possível de identificações sociais.

\footnotetext{
${ }^{2}$ Essa construção identitária da qual falamos caracteriza-se pela construção processual da identidade profissional do professor de Educação Física na educação infantil, refletindo as concepções e identificações significativas para o sujeito durante sua trajetória sócio-profissional.
} 


\section{Breve hISTÓRICO dA EduCAÇÃo Física NA EdUCAÇÃo INFANTIL dO MUNICÍPIO INVESTIGADO}

De forma resumida, descrevemos características do processo histórico de implantação da Educação Física no sistema de ensino do município de Vitória/ES, apontando alguns aspectos que contribuem com a construção de uma identidade para a área na educação infantil, assim como para o professor que trabalha neste nível educacional.

Em 1991 ocorre a inserção da educação física na educação infantil do município e perdura até 1996, quando a secretária municipal de Educação da época determina a retirada da disciplina deste nível educativo. Nos estudos mais recentes não se encontram explicações e razões para essa decisão (BERTO; NUNES, 2009, ANDRADE FILHO; FREITAS, 2007, ANDRADE FILHO, 2008), apenas a constatação de uma contradição, já que no ano de 1996, a Lei de Diretrizes e Bases da Educação, apresenta a educação infantil como primeira etapa da educação básica e a Educação Física como componente obrigatório (artigo 26, parágrafo $3^{\circ}$ ).

Em 2004 a Secretaria Municipal de Educação (SEME), em conjunto com professores do ensino superior, inicia um processo de reinserção desta disciplina nos Centros Municipais de Educação Infantil (CMEIs), através do projeto piloto intitulado "Projeto de Implantação das Disciplinas Educação Física e Artes Visuais na Proposta de Educação Infantil do Sistema de Educação Básica". Diante de repercussão positiva do projeto, no ano de 2005 a prefeitura municipal abre concursos públicos para a contratação efetiva destes profissionais.

A história mostra um processo de retirada e inserção que influencia a legitimidade da educação física nessas instituições de educação infantil, suscitando tensões e incertezas diante da construção da identidade da área neste espaço educativo, assim como da identidade do professor de educação física. 


\section{INFORMAÇõES METODOLÓGICAS DA EXPERIÊNCIADE ANÁLISE}

Para compreender os conceitos trabalhados por Dubar (1997, 2006), que são centrais no estudo em desenvolvimento, realizamos uma análise das relações profissionais vividas por uma professora de Educação Física da rede municipal de educação infantil, atuante como professora efetiva desde o ano de 2006.

O instrumento utilizado foi uma entrevista narrativa piloto ${ }^{3}$ sobre a temática das identidades docente, realizada em abril de 2010, identificando algumas relações possíveis entre o contexto institucional da educação infantil e as identidades docente da professora de Educação Física.

Ao "dar voz" a esta professora, diante da sua trajetória profissional e do contexto de trabalho, possibilitamos uma reflexão sobre o seu cotidiano profissional, evidenciando a importância da subjetividade nas análises da sua profissão e nos processos de construção das identidades, apontando a articulação da análise individual em um contexto mais amplo, pois como nos lembra Dubar (2006, prefácio, p. I e II) vivemos em um contexto em que uma "[...] identidade é construída pelos próprios indivíduos no decurso das suas trajectórias de vida com a contribuição das instituições e do socialcomunitário, e, portanto, das interacções."

O diálogo entre as narrativas da professora e a teoria da socialização das relações profissionais, possibilitou o exercício de

\footnotetext{
${ }^{3} A$ entrevista é caracterizada como piloto, pois constitui atividade exigida na disciplina Formação Docente em Educação Física de um PPGEF. Diante das informações coletadas, identificamos que englobava elementos centrais de análise sobre a identidade do professor de educação física da educação infantil, sendo por isso incluída como ensaio sobre a temática da identidade docente na dissertação de mestrado. Utilizamos como instrumento de coleta de dados uma entrevista narrativa realizada no CMEI no qual a professora trabalhava. Segue o roteiro para melhor compreensão: 1) Inserção da Educação Física na educação infantil; 2) Experiências marcantes da trajetória (início, decorrer e atualidade) como professora de educação física na educação infantil; 3) Percepção que os outros sujeitos que trabalham no CMEI tem do trabalho da professora; 4) Contexto da instituição na qual trabalha; 5) Influência desse contexto no modo de ser professor e nas suas aulas; 6) Entendimento de identidade docente; 7) Elementos constituintes da identidade docente; 8) Características do ser professora do ensino fundamental e/ou médio e ser professora da educação infantil.
} 
mobilização de alguns conceitos ${ }^{4}$, sobretudo, o de identidades, identificando as possibilidades de desenvolver um trabalho de análise no âmbito educacional ${ }^{5}$. Figueiredo (2010) aponta que, com o rigor de não fazer uma simples transposição ou engessamento teórico, é possível pensar algumas das questões e configurações identitárias analisadas por Claude Dubar, também, no âmbito do trabalho docente, e afirma que no campo da Educação Física, ainda é pouco expressivo os estudos sobre a temática.

\section{EM QUESTÃO: AS IDENTIDADES}

O exercício de análise das informações dialogadas com uma professora de educação física que atua cotidianamente em uma instituição educativa infantil, nos mostrou que é possível mobilizar os conceitos trabalhados pela sociologia das relações profissionais, tais como: identidades para si e identidades para o outro; conversões identitárias; negociação identitária; estratégias identitárias e crise das identidades, com fins a melhor compreender a discussão sobre identidade docente, construída no âmbito educacional.

Dubar (1997) fala de identidades, no plural, pois trata as identidades de forma complexa e ambígua, evidenciando a existência de múltiplas pertenças sociais. O percurso profissional da professora envolve experiências com várias faixas etárias em diferentes níveis educativos, em espaços de trabalho variados, bem como uma diversidade de experiências, por ter trabalhado em quatro CMEIs, afirmando que foram "quatro realidades totalmente diferentes", o

\footnotetext{
${ }^{4}$ Identidades para si e identidades para o outro, conversões identitárias, negociação identitária, estratégias identitárias e crise das identidades. Explorados no próximo item do artigo.

${ }^{5}$ Os estudos empíricos de Dubar apresentam como lócus de pesquisa as indústrias e empresas, mas entendemos ser possível uma análise também no âmbito educacional, já que a profissão professor evidencia uma identidade profissional. Lembramos que as identidades sociais para Dubar constituem-se como o resultado de processos de socialização, evidenciando as múltiplas pertenças dos indivíduos. Assim, as identidades profissionais referem-se àquelas construídas em espaços de socialização profissionais, evidenciando processos relacionais característicos do universo profissional, como no caso dos profissionais do magistério.
}

Movimento, Porto Alegre, v. 17, n. 04, p. 65-81, out/dez de 2011. 
que pode evidenciar um amplo universo de identificações e de socialização possíveis.

Socializar-se é "[...] assumir pessoalmente as atitudes do grupo que, sem nos apercebermos, guiam as nossas condutas" (PERCHERON, 1974 apud DUBAR, 1997, p. 31). As identidades para Dubar são resultados de processos de socialização variados, que relacionam o individual e o coletivo. $\mathrm{O}$ autor atribui uma importância à socialização, pois constitui um processo de identificação, de pertença a grupos e de relação, que trazem a perspectiva de (re)negociações na construção das identidades.

Em um contexto profissional podemos identificar a existência de variados grupos, constituídos por diferentes profissionais, comportando relações diversas dentro do espaço de trabalho, caracterizando múltiplos processos de socialização. Em convergência com esse pensamento, Lahire (2002) afirma que dentro dos espaços institucionais aparentemente homogêneos, podemos ver, também, diferenças internas importantes nos tipos de interação que ocorrem nas situações sociais vividas.

Pudemos identificar e compreender na narrativa da professora colaboradora que há, no contexto no qual ela está inserida, variados grupos e relações diversas, tais como o grupo das professoras regentes (de sala) que é percebido como um dos elementos de referência para a construção de uma identidade de professora de educação física, quando afirma que há "coisas" que "a professora regente pode e o professor de educação física não pode e não se tem uma resposta do porque, simplesmente porque você é professor de educação física e você não pode [grifos nossos]", evidenciando diferenças nas relações e interações mantidas pelos sujeitos, que podem desembocar numa hierarquização de funções, associada ao reconhecimento e legitimação de diferentes profissionais dentro do espaço de trabalho, sendo, por isso, fator de influência na construção da identidade docente. 
Evidenciamos alguns processos de socialização entre a professora de educação física e outros sujeitos adultos para além das regentes de classe, mas é necessário refletir, também, sobre como se desenvolve os processos de socialização da professora com as crianças.

As crianças foram caracterizadas pela professora como sujeitos que influenciam a sua construção identitária, a partir do momento em que o que estava em jogo era a construção de uma identidade de professora $^{6}$ de educação física para eles e para ela. Afirma que "[...] o menino chega e não sabe quem eu sou [...] a criança não sabia quem eu era, ela achava que eu era mais alguém para tomar conta". A identidade construída pelas crianças que diziam é a "tia de brincadeira" incomodava a professora que se sentia desvalorizada em sua profissão - "poxa, eu sou só uma tia de brincadeira?

Compreendemos que os processos relacionais são importantes na construção da identidade docente, pois refletem múltiplas formas de representação do professor, contribuindo com a (re)estruturação das identidades. Identificamos, também, a importância dada à comunicação, especialmente através da linguagem oral como elemento crucial dos processos de socialização e de identificação, possibilitando a configuração de sistemas de palavras que constituem os modos de identificação, que são historicamente variáveis, no processo de construção das identidades (DUBAR, 2006).

Cabe perguntar, então: como as crianças menores, que também estabelecem relações com a professora dentro do CMEI, mas que ainda não dominam a fala, se socializam com os professores? Como é possível dizer que essa criança menor socializa com o professor ao ponto de influenciar a sua identidade, quando a sua forma de comunicação ainda não é caracterizada pela linguagem oral?

Um elemento central a ser considerado é justamente essa possibilidade de socialização das crianças, por meio das suas próprias

\footnotetext{
${ }^{6}$ Esta identificação como "Professora" aparece com muita ênfase nas palavras da professora colaboradora, evidenciando uma identificação significativa para ela diante da sua construção identitária. Chamar de "tia de brincadeira", por exemplo, é identificado por ela como uma forma de redução da sua função profissional, interferindo nas identidades docente.
} 
formas de comunicação corporal, que parece influenciar a professora em seus modos de ser docente. Entendemos que as relações de socialização entre a professora e essas crianças perpassam o contato corporal direto, a proximidade e a afetividade entre elas. A percepção da professora sobre as necessidades socioeducativas desta faixa etária e das singularidades, constitui elemento de influência na construção da identidade docente no contexto educativo infantil ${ }^{7}$.

A instituição e sua organização também é um dos elementos que evidencia especificidades nas socializações profissionais. A colaboradora evidencia o cuidar e a rotina como elementos associados a questões muito subjetivas, que promovem contradições, diferenças de concepções entre os diferentes sujeitos inseridos neste espaço-tempo educacional, que deixam a prática de trabalho muito confusa.

[...] quando você trata com o cuidar não existe uma técnica, não existe uma regra, cada família cuida de um jeito, cada pessoa tem uma visão diferente de se cuidar, então isso influencia muito, por exemplo, se você cuida de uma maneira e outra pessoa se acha no direito de achar que aquilo não é legal, então torna o dia muito confuso, torna a prática muito confusa [...] muitas vezes desestimula a gente a ser professor de educação infantil.

Entendemos também que o cuidar e as rotinas são fatores importantes e característicos para a compreensão das singularidades no contexto da educação infantil, pois postulam outros saberes-fazeres aos profissionais, constituindo elementos de organização característicos da educação infantil ${ }^{8}$. Assim, talvez a percepção da professora evidencie a necessidade do próprio profissional

\footnotetext{
${ }^{7}$ Entendemos que a influência das crianças na construção da identidade docente evidencia uma perspectiva epistemológica diferenciada de estudo que envolve a criança como sujeito ativo nos processos relacionais. Ver mais a esse respeito na tese intitulada "Experiências de Movimento Corporal de Crianças no Cotidiano da Educação Infantil" (ANDRADE FILHO, 2011). Essa tese traz postulados da sociologia da infância para discutir a criança como sujeito de direitos.

${ }^{8}$ Percebe-se que as crianças, e suas singularidades, influenciam também a organização e o funcionamento da instituição. Identificamos, por exemplo, o cuidar como um dos elementos de organização associado às necessidades das crianças e assim, influencia o trabalho e a identidade dos professores.
}

Movimento, Porto Alegre, v. 17, n. 04, p. 65-81, out/dez de 2011. 
compreender as relações existentes entre as especificidades do lugar e a identidade docente, podendo contribuir com um desenvolvimento do trabalho de forma mais coerente.

O cuidar também aparece como parâmetro que permite que a colaboradora aponte diferenças entre ser professora no contexto da educação infantil e ser professora no ensino fundamental e/ou médio, explicitando a percepção do sujeito sobre como a organização institucional pode afetar seu trabalho e sua prática pedagógica.

$\mathrm{Na}$ educação infantil [...] fica muito no subjetivo [...] você começa a se prender em um monte de coisinhas que você acaba travando aulas que você não faz porque vai machucar. Já no fundamental você nem pensa nisso, acho que tem esse grau de dificuldade, vou alertar as crianças, mas você faz. Aqui não, você sabe que a criança consegue superar muito bem aquele obstáculo, você é a professora dele, mas você fala não vou fazer não, porque se eu fizer vai me falar que vai cair, vai me dar trabalho. $\mathrm{E}$ não é só pelo trabalho, é que vai ficar tanto no imaginário que você acaba tirando. [...] e aí minha angústia é que vai empobrecendo uma coisa que era tão legal, vai ficando maçante, vai me desestimulando muito? .

Percebemos que as maneiras de a professora se identificar na profissão, neste caso, através da produção do trabalho docente, sofrem desestabilizações diante de uma estagnação do processo de ensino-aprendizagem na educação infantil, dificultando a construção da sua identidade docente. Ela afirma que "[...] você perde muito quando não consegue produzir e a coisa não vai pra frente, você fica meio limitado na sua identidade. Pôxa! O que eu sou? Sou professor. E cadê o que não anda, cadê que a coisa não acontece".

Identificamos a existência de uma identidade reivindicada pela própria professora, caracterizando a identidade para si, construída

\footnotetext{
${ }^{9}$ Não é objeto de análise em nosso ensaio, mas chamou-nos atenção a presença de um risco que as experiências pedagógicas são submetidas diante da lógica do cuidar. $O$ enfoque ao cuidar pode provocar um "empobrecimento" pedagógico, constituindo elemento de influência identitária.
}

Vovimento, Porto Alegre, v. 17, n. 04, p. 65-81, out/dez de 2011. 
com categorias consideradas acessíveis e valorizantes pelo próprio sujeito, bem como uma identidade que é atribuída pelos outros à professora, constituindo a identidade para o outro, elaboradas em um espaço social determinado, diante dos sistemas de ação vivenciados (DUBAR, 1997).

A articulação entre estes dois conceitos constitui a chave do processo de construção das identidades, pois através deste "diálogo" é possível perceber as representações e maneiras de identificar de cada sujeito, assim como das instituições. Além disso, esta articulação pode apontar um processo de continuidade entre as duas formas de representação e identificação ou também uma descontinuidade/ ruptura quando a identidade para si difere da identidade para o outro. Podemos exemplificar este segundo caso com a incompatibilidade entre a identidade de "tia de brincadeira" construída pelas crianças e a identidade de professora reivindicada por ela própria. Desta descontinuidade, que incomodou a professora, desenvolveu um processo de desconstrução/reconstrução identitária, afirmando que "Agora eles sabem que eu sou a professora de educação física, tem uma identidade de educação física [...]", evidenciando uma conversão identitária (DUBAR, 1997) que se referem às transformações das identidades.

O desacordo identitário abre espaço para as estratégias identitárias, que visam diminuir o desvio entre as identidades atribuídas por outros e as identidades incorporadas pelo indivíduo (DUBAR, 1997). Percebemos que a professora colaboradora, diante da descaracterização do papel a ser desenvolvido por ela, enquanto professora de educação física dentro do CMEI, recorre à utilização de estratégias identitárias na tentativa de que seu trabalho fosse realizado de uma maneira em que ela conseguisse estabelecer suas identificações no espaço profissional, quando afirma que "[...] ficava na sala de aula e aí comecei a tentar criar dentro daquele contexto de quatro horas e meia, aí eu peguei e comecei a criar brincadeiras, formas variadas de trabalhar o movimento [...]".

Outro exemplo de estratégias é a visibilidade que os professores, algumas vezes, buscam dar ao seu trabalho dentro das instituições 
educativas, com a utilização de imagens (fotografias), a elaboração de diários, de planejamentos, entre outros, que estão atrelados a uma busca por reconhecimento profissional, estando em jogo a construção de uma imagem profissional, tanto pelos pares (colegas de trabalho, sujeitos da instituição) quanto pela comunidade do entorno escolar. A construção desta imagem põe em causa os conhecimentos adquiridos e mobilizados pelo professor em suas ações no cotidiano profissional, apontando que os espaços de reconhecimento são inseparáveis dos espaços de legitimação dos saberes e competências associadas às identidades (DUBAR, 1997).

Nota-se que os processos de identificação, tanto para si quanto para o outro, reflete a existência de diferentes categorias socialmente disponíveis de identificação ${ }^{10}$ para os sujeitos. A colaboradora identifica, por exemplo, que a visão de educação física dos outros sujeitos do CMEI relaciona-se com uma visão midiática que é incompatível com as visões e identificações dela.

A função de "dinamizador"1" representa uma categoria de identificação disponível que traz em si formas de representação que podem ser aceitas ou recusadas pelos profissionais de Educação Física e de Artes.

Em trabalho anterior ${ }^{12}$, identificamos que em algumas instituições os professores de educação física não gostam desta

\footnotetext{
${ }^{10}$ No processo de construção das identidades recorre-se a categorias que irão caracterizar a identidade estabelecida. Estas categorias permitem que os sujeitos tenham embasamento em construções consideradas legítimas por eles diante do processo de identificação de algo ou de alguém. Dubar (1997) traz, por exemplo, que há diferentes categorias socialmente disponíveis a níveis diferentes, como nomeações de Estado, étnicas, regionais, profissionais, etc. Devemos lembrar que estas categorias para serem formas de identificação devem ser legítimas para os indivíduos que as utilizam.

${ }^{11}$ Os Dinamizadores correspondem aos profissionais da Educação Física e de Artes que passaram a atuar na educação infantil do município, a partir de 2006. Esta nomeação é utilizada, pois se entende que a educação infantil não deve trabalhar com a lógica de disciplinarização como acontece no ensino fundamental devido às singularidades das crianças em serem vistos como sujeitos integrais, ou seja, não podemos separar as dimensões na criança.

${ }^{12}$ Trabalho de conclusão de um curso de Licenciatura em Educação Física de um Centro de Educação Física e Desportos de uma universidade federal, apresentado em 2009.
} 
nomeação, pois os outros sujeitos não os tratam como professores, ou seja, há uma representação diante desta categoria de identificação disponível, como a função de cobrir os momentos de planejamento das professoras regentes, que conflita com as aspirações identitárias dos professores.

O processo de construção das identidades aqui apresentado revela a existência de uma negociação identitária, que torna central o desenvolvimento de um processo comunicacional entre as identidades individuais e sociais. Esta negociação constitui um processo complexo que "implica fazer da qualidade das relações com o outro um critério e um desafio importante da dinâmica das identidades" (DUBAR, 1997, p.108).

Outro conceito importante de Dubar (2006) mobilizado na análise da entrevista narrativa é a noção de crise das identidades. Identificamos alguns momentos em que a professora questiona seu trabalho e sua permanência na educação infantil diante dos conflitos de identificações para si e identificações para o outro, evidenciando a presença de tensões diante da construção da identidade do professor de educação física na educação infantil. Esta situação está relacionada com a idéia de crise trazida por Dubar?

Dubar (2006, p. 14) utiliza a noção de crise como fase difícil vivida por um grupo ou um indivíduo e ruptura de equilíbrio entre diversas componentes, afirmando que "[...] as crises de identidade podem ser pensadas como perturbações de relações relativamente estáveis entre elementos estruturantes da atividade," sendo a identificação a atividade posta em causa na obra do autor.

É necessário esclarecer que o autor trata de uma crise de contexto e não uma crise pessoal, já que a crise das identidades explicitada está associada com a mudança entre diferentes modos de identificação social (comunitário e societário), evidenciando transformações nas relações sociais e sistemas de ação vivenciados em contextos específicos que exprimem rupturas nas referências identitárias, abrindo espaço para o incerto, o não-definido e a 
possibilidade de conversões identitárias. É central nas crises de Dubar um desequilíbrio das bases de construção das identidades, mais uma vez contribuindo com a identificação da relação entre a identidade individual e as identidades coletivas.

Dubar (2006) associa a crise das identidades à crise da modernidade, pontuando que esta é consequiência de mutações em três esferas centrais da vida social: a transformação nas relações de gênero e da instituição familiar; a esfera do trabalho, emprego, formação e escolarização e a esfera do Estado-nação, contribuindo com a fragmentação das identidades. Estas variadas mutações que estão associadas com as transformações nas formas de identificação possíveis.

Identificamos alguns acontecimentos históricos que contribuíram/contribuem com o desenvolvimento de uma crise das identidades e com a construção da identidade docente.

As discussões que permeiam a área acadêmica da Educação Física constituem elemento de influência na construção da identidade do professor desta disciplina, pois lida com os objetivos sócioeducativos e conhecimentos específicos deste campo. A crise epistemológica da área, instaurada desde a década de 1980, caracteriza-se como um fator de crise para as identidades dos professores quando questiona as bases de identificação e de sustentação dessa disciplina nos espaços de trabalho, refletindo no cotidiano dos professores que atuam na educação básica um dilema de identificações. Conforme indica Figueiredo (2010), diante de uma pesquisa com professores de educação física percebe-se a articulação de duas lógicas que conjugam ruptura com a identidade de professor ligada à performance e busca por um outro tipo de reconhecimento ou legitimação, associada à possibilidade de ensinar uma educação física qualitativamente diferenciada que possa ampliar as experiências sociocorporais dos alunos.

O processo histórico da educação infantil também pode configurar uma crise identitária dos professores que trabalham com as crianças pequenas quando da mudança do âmbito assistencialista 
para o âmbito educacional, constituindo uma modificação das referências e objetivos a serem desenvolvidos na educação infantil. Se pensarmos, por exemplo, na legalização da educação infantil à educação, identificamos uma modificação das concepções de criança e infância, assim como da lógica de trabalho a ser desenvolvida com as crianças pequenas, além da indicação à formação dos professores que deve ser coerente com as novas exigências educativas e com as necessidades das crianças refletindo uma identidade de educação infantil e dos profissionais que atuam neste nível educativo.

Podemos pensar ainda no processo de inserção da educação física na educação infantil do município em discussão, como um exemplo de desestruturações e reestruturações identitárias, que culmina em crises, quando identificamos um processo de afirmação e negação desta disciplina relacionado ao campo político e profissional. A "retirada" em 1996 evidencia um processo de perda das bases de identificação e, que conseqüentemente, apresentou um período de luta por construção de novos alicerces identitários, como a realização do projeto piloto. O grupo de professores envolvidos na elaboração do projeto piloto caracterizou-se como um grupo de referência identitária positiva para os professores de educação física da educação infantil, porém estas referências também passaram por transformações diante dos processos reais de configuração/implementação nas instituições educativas infantis que desestabilizaram o trabalho dos professores, culminando num processo de incertezas e transformações identitárias. A professora colaboradora afirma que a inserção da educação física na educação infantil "foi muito traumática porque eles fizeram um projeto piloto que foi muito legal e que a gente viu ótimos comentários, mas eles não souberam implantar esse projeto."

Essa mobilização de conceitos no âmbito das identidades traz possibilidades para a compreensão da complexidade da construção da identidade docente e também para compreender a relação indissociável entre as identidades individuais e as identidades coletivas, 
evidenciando que há um universo amplo de identificações, em diferentes âmbitos sociais, que influenciam direta ou indiretamente na construção das identidades no mundo da docência.

\section{Considerações FINAIS}

As identidades docente caracterizam-se como uma das identidades possíveis que permeiam o sujeito, pois é constitutiva do campo profissional, o que evidencia as múltiplas pertenças do sujeito, especialmente em épocas em que se torna difícil postular uma identidade única, já que há uma fragmentação dos referenciais de identificação, sendo o sujeito pertencente a campos familiares, políticos, sociais, profissionais, epistemológicos, etc. Refletir sobre a construção das identidades docente exige analisar relações institucionais, administrativas, coletivas, pessoais, etc. Foi o que tentamos materializar nesse artigo.

Compreendemos que o processo de escuta mobilizado nesse artigo, torna-se importante instrumento teórico e metodológico para a formação inicial, pela possibilidade de: trazer elementos de reflexão sobre o dia-a-dia profissional, com as variadas relações, as negociações entre os sujeitos, os conflitos, entre outros; de mobilizar conhecimentos pessoais e profissionais da docência que fomentem a perspectiva de o aluno formar-se professor no transcorrer da sua formação inicial, com perspectivas reais de uma intervenção profissional qualificada; de compreender a importância do lugar das narrativas nos estudos do ensino e da formação inicial e continuada de professores. Ao falar das experiências de formação e, no caso, da escuta das experiências das relações profissionais vividas por uma professora, os sujeitos em formação podem começar a compor singularidades de um percurso de formação docente. 
Identity construction of teacher of Physical Education in an institution of infant education Abstract: Is an article that seeks to understand how the Physical Education teacher builds their identities, relational considering the experiences lived by it with the organization of the institution where he works, with adult subjects and children, in the context of infant education. We built a narrative analysis of a physical education teacher at work in early infant education, seeking to work with some concepts from the field of professional socialization. We discuss the teacher's identities as a constituent of the possible identities of the subject in the professional field, which shows that multiple belongings subject to familiar fields, political, social, and professional.

Keywords: Teacher identity. Physical Education. Infant Education

Construción de la identidad de la maestra de Educación Física en un centro de educação infantil

Resumen: Es un artículo que trata de comprender cómo el profesor de Educación Física se basa su identidad, teniendo en cuenta las experiencias vividas por lo con la organización de la institución que trabaja con los sujetos adultos y con los niños, en el contexto de la educación infantil. Construimos un análisis de la narrativa de una maestra de educación física actuante en la educación infantil, buscando trabajar con algunos conceptos del campo de la socialización profesional. Discutimos las identidades docentes como una de las identidades posibles constitutivas del sujeto en el campo profesional, lo que evidencia las múltiplas pertenencias de ese sujeto a los campos familiares, políticos, sociales, profesionales.

Palabras clave: Identidad Docente. Educación Física. Educación Infantil

\section{REFERÊNCIAS}

ANDRADE FILHO, N.F. de. Experiências de movimento corporal de crianças no cotidiano da educação infantil. 2011. 285 f. Tese (Doutorado em Educação) - Faculdade de Educação da UNICAMP, Universidade Estadual de Campinas, São Paulo, 2011.

Movimento, Porto Alegre, v. 17, n. 04, p. 65-81, out/dez de 2011. 
Movimento corporal humano: objeto de estudo/ensino exclusivo ou específico da Educação Física para a educação infantil. In: ANDRADE FILHO, N. F. de; SCHNEIDER, O. Educação Física para a educação infantil: conhecimento e especificidade. São Cristóvão: Editora UFS, 2008. p. 177-225.

ANDRADE FILHO, N.F.de; FREITAS, L.L.L.de. Saberes mobilizados pelos professores de Educação Física na prática pedagógica com crianças de zero a três anos. In: CONGRESSO BRASILEIRO DE CIÊNCIAS DO ESPORTE, 15; CONGRESSO INTERNACIONALDE CIÊNCIASDOESPORTE/COLÉGIO BRASILEIRO DE CIÊNCIAS DO ESPORTE, 2., Recife, 2007. Anais... Disponível em: <http:// www.cbce.org.br/cd/resumos/171.pdf>. Acesso em: 2 mar. 2011.

BERTO, R. C.; NUNES, K. R. Políticas curriculares da educação física na educação infantil na rede municipal de ensino de Vitória/ES. In: SIMPÓSIO BRASILEIRO DE POLÍTICA E ADMINISTRAÇÃO DA EDUCAÇÃO, 24., Vitória, 2009. Disponível em: <http://www.anpae.org.br/congressos_antigos/simposio2009/175.pdf>. Acesso em 10 mar. 2011.

BRASIL. Lei no 9.394/96, de 20 de dezembro de 1996. Disponível em: <http:// portal.mec.gov.br/arquivos/pdf/ldb.pdf>. Acesso em: 2 mar. 2011.

DUBAR, C. A crise das identidades. A interpretação de uma mutação. Tradução Catarina Matos. Porto: Edições Afrontamento, 2006.

A Socialização: construção das identidades sociais e profissionais. Tradução Annette Pierrette R. Botelho e Estela Pinto Ribeiro Lamas. Porto: Porto, 1997.

FIGUEIREDO, Z.C.C. Experiências profissionais, identidades e formação docente em Educação Física. Revista Portuguesa de Educação, Minho, p. 153-172, 2010.

LAHIRE, B. O homem plural: os determinantes da ação. Tradução Jaime A. Clasen. Petrópolis, RJ: Vozes, 2002.

RODRIGUES, R.M. Rotina, educação física e educação infantil: notas de estudo. Monografia (Conclusão de Curso) - Centro de Educação Física e Desportos/UFES, 2009.

Endereço para correspondência:

Renata Marques Rodrigues

Rua Alameda das Orquídeas, 22

Valparaíso

Cep. 29165-786

Serra - ES

Recebido em: 13.05.2011

Aprovado em: 13.12.2011

lovimento, Porto Alegre, v. 17, n. 04, p. 65-81, out/dez de 2011. 
